\title{
PATIENTS ARE A VIRTUE
}

The BDJ Upfront section includes editorials, letters, news, book reviews and interviews. Please direct your correspondence to the News Editor, Kate Quinlan at the BDJ, The Macmillan Building, 4 Crinan Street, London, N1 9XW or by email to k.quinlan@nature.com

Press releases or articles may be edited, and should include a colour photograph if possible.

Stephen Hancocks OBE

Editor-in-Chief

$\mathrm{M}$ any years ago at denta school I wrote a sketch for the hospital Christmas Revue about a lady with the first name of Patience who married a man with the surname Patient. Attempting to make an appointment in a busy department of the dental hospital she had to keep holding on the telephone and thus became Patience Patient the Patient Patient. How surprised she would be in the twenty-first century to learn that she was now a consumer rather than a patient.

When I travel on a train or plane I think of myself as a passenger, when I eat in a restaurant I am a diner and when I consult a health professional I am a patient. Am I old fashioned? Am I alone? Do the majority of those who seek our help, care and treatment on a regular basis think of themselves as patients or as consumers?

Part of the problem is due to a confusion between service and outcome. Thus various parties involved in dentistry have become muddled of recent times about the meaning of service in the context of dental practice. Way back in the last century when caries was rife, complete dentures were commonplace and having a mobile phone meant that you had a long enough cable on it to carry it across the living room we were all shocked by the contentions of certain business gurus who declared that dentists were in competition for the discretionary spending power of consumers who might instead chose foreign holidays or haircuts over dental care. The consequent tailspin resulted in acres of new carpet being laid in waiting rooms (excuse me, reception

\section{'Do those who seek \\ our care see themselves as patients or as} consumers?' not have heralded a change in the
actual dental care they received. While the non-clinical service showed improvement the outcome remained the same; quality clinical dentistry provided by a trained and experienced professional. I am sure that the overwhelming majority of the patients of every reader of this editorial choose to return to see him or her for advice and treatment not because they are reminded of a supermarket chain, nor because they have gone to a price comparison website to discover if they are getting the best deal but because they like and trust you.

What we each like and trust varies enormously, that is the nature of the human condition and thanks to the way in which we organise our society we have the opportunity to express and exert our choices. Amongst these decisions are the supermarkets we patronise, or not. What makes us choose? Location, convenience, price, quality, our own status?

Probably a combination of all these things and probably a similar process of selection as we might make in choosing, and maintaining, visits to a dentist or dental practice. The essential difference between say, Lidl and Waitrose, as alluded to in recent opinion and debate is that a branded tin of say, baked beans, in each has exactly the same outcome - a tasty snack on toast. Similarly, a clinical intervention will also have a similar quality controlled outcome irrespective of whether there is a Bach piano concerto, Status Quo or One Direction playing in the background.

So, there is nothing wrong with choice, nor with providing a range of varied services. The key essential here is that dentists are competent and that the treatment they provide is safe and effective as dictated and guided by scientific rigour, regulation and standards as generated and applied personally, institutionally, legally and ethically.

I get the feeling that there is a lack of perspective at work here. As I have written previously ${ }^{1}$ the current furore over the rise in complaints needs to be set against the background of the huge number of dental professionals registered and the millions of courses of treatment successfully provided in the UK year in, year out. We need to differentiate more carefully though. Failure to provide good clinical care is quite different from a complaint that someone in the practice 'looked at me in a funny way'.

Patient care is something that we are individually and collectively extremely good at. We are respected, frequently thanked and often commended by our patients whose trust in us is demonstrated by their loyalty over years and often decades and generations. We must be clear and vocal that this is quite different from customer care, client care, consumer care or any other type of care. Patience was under no illusion all that time ago and her care is as relevant to us today as it was then.

1. Hancocks S. I want to complain. Br Dent J $2014 ; 11: 605$.

DOI: 10.1038/sj.bdj.2014.599 